\title{
Cost-effectiveness of high-sensitivity faecal immunochemical test and colonoscopy screening for colorectal cancer
}

Mattias Aronsson, Per Carlsson, Lars-Åke Levin, J . Häger and R. Hultcrantz

The self-archived version of this journal article is available at Linköping University Institutional Repository (DiVA):

http:// urn.kb.se/ resolve?urn=urn:nbn:se:liu:diva-139394

N.B.: When citing this work, cite the original publication.

Aronsson, M., Carlsson, P., Levin, L., Häger, J., Hultcrantz, R., (2017), Cost-effectiveness of highsensitivity faecal immunochemical test and colonoscopy screening for colorectal cancer, British J ournal of Surgery, 104(8), 1078-1086. https:// doi.org/ 10.1002/ bjs.10536

Original publication available at:

https:// doi.org/ 10.1002/bjs.10536

Copyright: Wiley: 12 months

http:// eu.wiley.com/WileyCDA/ 
Cost-effectiveness of population screening for colorectal cancer in Sweden: a comparison of high sensitive faecal immunochemical test and colonoscopy

Mattias Aronsson M.Sc. ${ }^{1}$, Per Carlsson Ph.D. ${ }^{1}$, Lars-Åke Levin Ph.D. ${ }^{1}$, Jakob Hager MD, $\mathrm{PhD}^{2}$, Rolf Hultcrantz MD, $\mathrm{PhD}^{3}$.

${ }^{1}$ Department of Medical and Health Sciences, Linkoping University, Linkoping, Sweden

${ }^{2}$ Department of Surgery and Department of Clinical and Experimental Medicine, Linköping University, Norrkoping, Sweden

${ }^{3}$ Department of Gastroenterology and Hepatology, Karolinska Institute, Karolinska University Hospital, Solna, Sweden

Version: 2016-05-26

Source of funding: Funded by the SCREESCO study

Manuscript category: Original article

Word count (excl. references, abstract, tables and legends): 3184

Keywords: Colorectal cancer, Cost-effectiveness analysis, Screening

*Corresponding Author:

Mattias Aronsson, M.Sc.

Linkoping University - Centre for Medical Technology Assessment

Department of Medical and Health Sciences

Linkoping University

SE-581 83 Linkoping, Sweden

Phone: +46 736219021

Fax: +46 101034995

Email: mattias.aronsson@liu.se 


\section{ABSTRACT}

\section{Background}

Colorectal cancer (CRC) screening can decrease morbidity and mortality. However, there are widespread differences with respect to the implementation of programmes and choice of strategy. Our primary objective is to estimate lifelong costs and health outcomes of two of the currently most preferred methods to screen for CRC, colonoscopy and sensitive faecal immunochemical test (FIT).

\section{Method}

The cost-effectiveness analysis of CRC screening in a Swedish population was performed using a decision-analytic model, which was based on the design of the SCREESCO-study and data from the published literature and registries. Lifelong cost and effects of colonoscopy once, colonoscopy every $10^{\text {th }}$ year, FIT twice, FIT biennially and no screening were estimated using simulations.

\section{Results}

The analysis showed that when 1000 individuals were invited to screening once with colonoscopy, it implied 45 more quality-adjusted life-years (QALYs) and a cost-saving of €64, 800 compared to no screening. Similarly, screening twice with FIT implied 26 more QALYs to a cost saving of $€ 17,600$. If the colonoscopy screening was repeated every $10^{\text {th }}$ year, the method implied 7 additional QALYs to a cost of $€ 189,400$ compared to one round. The additional gain of biennial FIT screening was 25 QALYs to a cost of $€ 154,300$.

\section{Conclusion}

All screening strategies were cost-effective compared to no screening. Repeated and unrepeated screening with colonoscopy were more cost-effective than FIT when lifelong effects and costs were considered. However, other factors such as patient acceptability of the test and availability of human resources also have to be considered.

Keywords: Colorectal cancer, Cost-effectiveness analysis, Screening 


\section{INTRODUCTION}

Colorectal cancer (CRC) is the third most commonly diagnosed cancer in the world ${ }^{1}$ and is associated with mortality and sufferings in the affected individuals and high costs for the society. Its natural history and the polyp-cancer pathway have been well known for several decades. Cancer can be prevented to a large extent by removing the polyps. In addition, the early-stage detection of CRC often implies lower mortality rates. Hence, several guidelines, such as the US preventive service task force, ${ }^{2,3}$ the Gastroenterology multi-society task force, ${ }^{4,5}$ and the American Cancer Society, ${ }^{6}$ have recommended CRC screening for asymptomatic average-risk individuals., 8

Several methods with different attributes, e.g. colonoscopy (OC), faecal occult blood test (FOBT), faecal immunochemical test (FIT), and sigmoidoscopy, are already in use in screening programs. However, there is a widespread difference in the implementation status and strategies followed between countries. ${ }^{9}$ All the screening options are considered to imply clinical benefits ${ }^{10-12}$ and have different impacts on the limited health care resources (e.g. supply of endoscopists). ${ }^{13}$ Two of the most preferred methods for screening for CRC are OC and FIT. ${ }^{9}$ OC is often seen as the 'golden standard' while FIT, followed by OC when FIT is positive, is less sensitive but has higher participation rates and limits the need for OC. Both methods have previously been shown to be clinical- and costeffective compared to no screening. ${ }^{14-18}$ However, the relative effectiveness of these screening methods is yet to be studied head-to-head for different programme designs.

The Screening of Swedish Colons (SCREESCO)-study (NCT02078804) is a randomised controlled trial (RCT) on CRC screening, which is sponsored by and run in 18 of the 21 Swedish county councils with a total population of 7.5 million. The study is three-armed and has an inclusion time of three years. All participants will be 60 years old when they are included. For this study, 20,000 persons will be invited to an OC, 60,000 persons will be invited to do a high-sensitive (cut-off value $10 \mu \mathrm{g}$ ) FIT year one and three, and 120,000 persons will serve as controls. The follow-up period is 15 years.

As the screening methods and the clinical panorama surrounding the screening programs constantly change (for instance, new technology to treat CRC or the disease incidence), one have to considered a 
'moving target' when the most appropriate alternative shall be chosen. The clinical and economic effects of specific screening options and the optimal way to screen a population change over time. This implies that it could be unwise to wait for long-term follow-up data from RCTs of screening programs before making decisions about implementation, as the results of the studies and the technology itself can be outdated when such data becomes available. Hence, new and updated simulation models to make informed predictions about the future area is a continuous need as a complement to clinical studies for decision makers.

Therefore, our primary aim is to estimate the long-term costs and health outcomes of four strategies for CRC screening compared to no screening. This is based on the recently available data in the scientific literature and early experience from the SCREESCO-study.

A secondary aim is to calculate the uncertainties in the cost-effectiveness results and single model inputs, such as the importance of the participation rate, the age of the screening initiation and the disease progression.

\section{METHODS}

\section{Model overview}

The cost-effectiveness analysis of CRC screening was based on a decision-analytic Markov model. The parameter data used in this study were mainly obtained from the published literature and early experience from the SCREESCO-study. In the model, the remaining life of a hypothetical population of Swedish 60-year-olds was simulated with an emphasis on CRC and its disease progression, polyppathway, detection and treatment. The model consists of a number of different health states which the simulated individuals can experience. Moreover, the model deploys fixed-time cycles, and in every cycle, the simulated individual has a certain probability to move to another health state. The probabilities to stay or transition into another health state, together with risks of various events, were obtained from the published scientific literature. The model was developed in Microsoft Excel, 
deployed a life-long time horizon, had a health-care payer perspective and used 1-year cycles in which transitions could take place. We used an annual discount rate of three percent for both effects and costs as the base-case per recommendation from the Swedish authorities. ${ }^{19}$ Discounting is the practice of weighting future gains and losses less heavily than those that occur in the present. This is done to account for that individuals due to uncertainty typically prefer benefits now rather than delay the same benefits until sometimes in the future. The starting age of 60 years was chosen in this analysis as this was the age when individuals were invited to screening in the SCREESCO-study. Figure 1 is a schematic figure of the model structure and shows the most important health-states and other components.

[Figure 1]

\section{Simulation overview}

The cornerstone in the model is the simulation of the disease progression and the impact of screening. When the simulation starts at the age of 60 years, all simulated individuals are invited to screening, in which they may or may not participate. At that time, all individuals are either in the health state "Normal bowel" or in a health state with currently undiagnosed adenoma or CRC: "Low-risk adenoma”, ”High-risk adenoma”, “Local CRC”, “Regional CRC” or “Distant CRC”. According to Swedish clinical guidelines, low-risk adenomas are defined as $\leq 10 \mathrm{~mm}$, tubular growth, and lowgrade of dysplasia. High-risk adenomas are defined as having one of the following characteristics: $>10 \mathrm{~mm}$, tubovillous or villous growth, and high-grade of dysplasia. Health states representing CRC are defined per American Joint Committee on Cancer, where Stage I-II is represented by "Local CRC”, Stage III by “Regional CRC” and Stage IV by “Distant CRC”. Over time, there is a certain annual risk for individuals with a normal bowel to develop low-risk adenomas. Low-risk adenomas can with a yearly probability develop into high-risk adenomas, which can develop into undiagnosed CRC (the progression is described in the lower part of Figure 1). These progression rates are not well studied in the scientific literature. Therefore, we had to rely on indirect methods that used real-world prevalence/incidence data and mathematical methods for estimating the yearly progression rates. ${ }^{20}$ 
Further, in the model, there is a certain yearly probability that an unknown condition, e.g. adenoma or CRC, can be diagnosed, this can be done either by screening (left part of Figure 1) or spontaneous detection (opportunistic screening or by symptomatic presentation).

If adenomas are detected, they are assumed to be removed with further follow-up, and when CRC is detected, the disease is treated according to treatment guidelines. Patients with CRC have a risk of dying from the disease and also from procedure-related events if treated or screened. The annual mortality rates for patients diagnosed with local, regional, and distant CRC for the first five years were obtained directly from the Swedish national colorectal cancer registries (data from 20092013). ${ }^{21}$ CRC-related mortality was dependent on the age of the patient, the stage of cancer, and the time in the current cancer stage. From the $5^{\text {th }}$ year and afterwards, we extrapolated the mortality rates with cancer based on the mortality in the previous years by using Weibull-curves. The procedurerelated mortality from OCs was obtained from a meta-analysis of complications from the examinations. ${ }^{22}$ Irrespective of the bowel-status, all simulated individuals had a risk of dying from other causes (non-colorectal related). This standard mortality was dependent on the age and gender in the simulated individuals and was retrieved from the national statistics of the general population in Sweden. ${ }^{23}$

\section{Screening strategies}

In the model, we simulated five different screening strategies. In all the below program strategies, screening is initiated at the age of 60 years in both men and women. Three strategies were from the SCREESCO-study:

i. $\quad$ No screening

ii. Screening twice with FIT

iii. Screening once with OC.

As a reference, two additional screening strategies with repeated screening up to the age of 80 years were also simulated.

iv. Screening biennially with FIT 


\section{v. Screening every ten years with OC}

This selection was based on what we identified to be the most commonly used programs globally for screening with OC and FIT. ${ }^{9}$

\section{Screening parameters}

Data regarding the participation rates in the first round of screening were projected based on early experience in the SCREESCO-study and is shown in Table 1. In the case of repeated screening, in the population of hypothetical individuals, we assumed that 31\% could be categorised as 'never attendees' for FIT and 38\% for OC. Further, 40\% were categorised as 'always attendees' for FIT and $31 \%$ for OC. These numbers were calculated based on the early experience in the SCREESCO-study and a study of repeated screening in the UK. ${ }^{24}$ This means that these two subpopulations will never, respectively always, attend the screening, irrespective of the number of times they were invited to the screening. However, the attendance rate at consecutive invitation to screening was assumed to be the same as at the first invitation to screening. ${ }^{24,25}$ The specificity and sensitivity of OC were retrieved from a meta-analysis presented by Telford et al. ${ }^{26}$ and the corresponding parameters for FIT (cut-off value $10 \mu \mathrm{g}$ ) were obtained from Wijkerslooth et al. ${ }^{17}$.

\section{Utility weights}

Utility weights were applied to the simulated individuals in the model to create quality-adjusted lifeyears (QALYs). These utility weights included values ranging from 1 (representing full health) to 0 (representing death). The age-dependent baseline utility weights, based on the general population of Sweden, were obtained from Burström et al. ${ }^{27}$ The utility was adjusted for disease severity in individuals with cancer based on Ness et al. ${ }^{28}$ In the base-case scenario, screening procedures were not expected to affect the health-related quality of life. However, in the sensitivity analyses, we used published data about the willingness-to-pay to avoid OC to incorporate the potential discomfort of the procedure into the model..$^{29}$

\section{Unit costs and resource usage}


Parameter data regarding resource usage, in the case of cancer, was obtained from the Swedish Colorectal Cancer registry ${ }^{21}$ and Tilson et al. ${ }^{30}$. The unit costs for pharmaceuticals in patients treated with chemotherapy were gathered from FASS. ${ }^{31}$ Unit costs for visits and procedures were based on NordDRG ${ }^{32}$. Individuals attending OC were expected to miss one day of work. This implied a production loss of $€ 116$ (€27, 935/ 240 workdays), as obtained from national statistics of all individuals aged 60-64 years in the general population of Sweden ${ }^{23}$. All unit costs were adjusted to the year 2016 and converted to Euro using the exchange rate on June 1, 2016 (€1 = 9.3 SEK). Details of the cost data used in the model are presented together with other input data in Table 1 (and more detailed description with all data used in the model is provided in the supplementary materials).

\section{[Table 1]}

\section{Sensitivity analyses}

To assess for robustness of the model, the importance of uncertain parameters and assumptions made in the model were tested by varying the parameter value, and these are presented as two-way sensitivity analyses. The statistical uncertainty of the cost-effectiveness analysis was studied using Monte-Carlo simulations. The results of the simulation were analysed using cost-effectiveness planes and acceptability curves. The probability that the treatment is cost-effective was calculated using a conservative threshold of $€ 10000$ per gained QALY.

\section{RESULTS}

The model enabled lifelong simulations of 1000 60-year-old hypothetical individuals in each of the five different screening strategies (i-v). Depending on the strategies implemented, different participation and detection rate of colorectal-related conditions are expected. The incidence of CRC was reduced by $25 \%$ and $11.7 \%$ using colonoscopy once and FIT twice, respectively. The cumulative number of CRC-related deaths when 1000 hypothetical individuals are invited and simulated through the five different screening strategies (i-v) is shown in Figure 2. When only analysing screening programs used in the SCREESCO-study, OC (ii) implied the fewest number of CRC-deaths. 
However, repeated screening with OC after 10 years and FIT biennially resulted in the largest decrease in CRC-related deaths.

[Figure 2]

Figure 3 shows the cumulative net cost of the four strategies with screening compared to no screening. As presented in the figure, the screening performed in the SCREESCO-study implied a short-term cost increase but a long-term cost-saving. Repeated screening implied, as expected, higher total cumulative costs as shown by the spikes in the curves in the figure. This is due to costs occurring from the screening procedures.

[Figure 3]

Cost and effects (QALYs) per 1000 invited individuals of all the five different screening strategies are presented in Table 2. It should be noted that, compared to no screening, all four programs showed a reasonable cost per QALY but screening once with OC implied 49 gained QALYs gained to a lower cost, while OC every 10th year resulted in the largest gain of QALYs but to a total cost increase of $€ 124,600$. Screening with FIT twice and biennially also implied a low cost per gained QALY but corresponding strategies were associated with smaller gains of QALYs and higher costs compared to screening with OC (Table 2).

[Table 2]

\section{Sensitivity analysis}

The reliability of our results was tested using the sensitivity analysis. Table 3 presents the importance of assumptions and uncertain parameters for the health economic result. The result was, as in most screening programs, sensitive to changes in the discount rate. This is due to the fact that positive effects could be observed several years after the screening. OC was in relation to FIT more sensitive to changes in the starting age and the disease progression. As shown in the table, the costeffectiveness results were not sensitive to changes in the participation rates.

\section{[Table 3]}


The probabilistic sensitivity analysis showed that screening once with OC has the highest probability of being cost-effective if a QALY is considered to be worth $€ 10000$. The probability that each strategy was the most cost-effective was $46.2 \%, 1.1 \%, 29.0 \%$ and $13.1 \%$ for OC once, FIT twice, OC every 10th year and FIT every second year, respectively.

\section{DISCUSSION}

This study showed that screening for CRC is highly cost-effective; this result is similar to several previously published studies. ${ }^{13}$ However, the screening programs differ between countries in terms of timing of implementation and contextual differences such as different population preferences. The development of the test and new knowledge of the organisation of programs will continuously change the conditions and demand new assessments when new programs shall be implemented. Unlike previously published cost-effectiveness analyses, this study was partly based on screening data from early experience in a head-to-head study of OC and high-sensitive FIT. When these tests are compared, the often debated factor is the participation rate. Projected data from early experience in the SCREESCO-study showed a lower adherence to both OC (38\%) and FIT (50\%) than expected. Even if we use lower participation rates than e.g. were estimated in the study design, the investigated screening strategies in the SCREESCO-study implied both clinical and economic gains. OC once was dominant compared to screening with FIT twice, resulting in a better clinical outcome to lower costs when using a lifelong perspective in a Swedish context. This screening strategy also implied the lowest cost for gaining QALYs, but if the health care payer is prepared to pay more than €26,900 per QALY, additional QALYs can be gained to a reasonable cost using screening with OC every tenth year. Cost-effectiveness is one of the several aspects to consider in decisions regarding implementation of a CRC screening program. Even though investigated programmes these were not very sensitive to changes in the participation rates. Other factors such as patient acceptability of the test and availability of human resources have to be considered. Furthermore, OC is a rather complicated way of bowel examination, which requires sufficient access to OC facilities and a good quality of OC procedure. However, this is not the case in many countries. The shortage of 
endoscopists, and variability and quality of the examination are other aspects to consider and require further investigation.

Simulation models have certain limitations often due to the lack of accurate data on lifelong costs and effects for calculating the cost-effectiveness. Randomised clinical studies with sufficient follow-up time for capturing all relevant cost and effects are rarely available when economic evaluations must be made. Waiting for long-term follow-up data from the RCTs before making decisions about an implementation would imply an unacceptable time lag for technologies that are most likely effective. Hence, when long-term real-world or study data are absent and policy decisions are required to be made, well-grounded models based on the overall knowledge of the area are useful tools for decision makers. It is also important to update or construct new simulation models when better data becomes available. Furthermore, in order to draw conclusions from the model, uncertain parameters, such as the starting age, polyp pathway and disease progression, need to be rigorously studied in sensitivity analyses. For instance, as presented in Table 3, screening with both OC and FIT remained costeffective despite relatively large changes in these parameters, which reduces the uncertainty in the model predictions.

A limitation of this analysis, also present in most cost-effectiveness studies, is that it is difficult to include all types of effects occurring from the screening. For instance, a parameter that was not included in our analysis was the small but existing effect of false positive results on the quality of life. It is likely that such patients have increased levels of anxiety during a short time period. Including this parameter in our model could have a slightly negative effect on the result of screening.

Another limitation was that we only compared OC and FIT with no screening because these were used in the SCREESCO-study. In that study, a FIT test with high sensitivity was used in order to get more information if increased sensitivity leads to improved detection and survival in patients with CRC; but, this is usually not the case in screening programs. By using a less sensitive FIT test would probably result in less CRC but in lower costs, which imply that cost-effectiveness may not be affected. Moreover, several other screening technologies are available that should be studied in further 
analyses. For instance, CT colonoscopy has been shown to be a cost-effective screening alternative. ${ }^{42}$ A similar problem was that the SCREESCO-study only included three treatment arms: no screening, screening once with OC and twice with FIT. We added two additional treatment arms with repeated screening, but in a real-world context, there are more options in terms of when the screening is initiated, how often it is repeated and the possibility of different combinations of screening methods in the same program. For instance, the sensitivity analysis presented in Table 3 shows that the starting age of the screening affect the cost-effectiveness. Further studies should analyse at what age the screening should start and when the screening should be repeated to optimize the program.

\section{CONCLUSION}

All strategies that included screening were cost-effective compared to no screening. Repeated and unrepeated screening with colonoscopy were more cost-effective than FIT when lifelong effects and costs were considered. Screening with OC once implied the lowest cost for gaining QALYs while screening every tenth year gained additional QALYs to a reasonable cost. However, other factors such as patient acceptability of the test and availability of human resources also have to be considered.

\section{ACKNOWLEDGEMENT}

We would like to express our sincere gratitude to the Swedish counties, RCC i samverkan, The Swedish cancer foundation and Karolinska Institutet for all their support during this work.

\section{REFERENCES}

1. Ferlay J, Soerjomataram I, Dikshit R, Eser S, Mathers C, Rebelo M, et al. Cancer incidence and mortality worldwide: sources, methods and major patterns in GLOBOCAN 2012. Int J Cancer 2015;136(5): E359-386. 
2. US Preventive Services Task Force. Screening for colorectal cancer: recommendation and rationale. Am Fam Physician 2002;66(12): 2287-2290.

3. US Preventive Services Task Force. Screening for colorectal cancer: U.S. Preventive Services Task Force recommendation statement. Ann Intern Med 2008;149(9): 627-637.

4. Winawer SJ, Zauber AG, Fletcher RH, Stillman JS, O'Brien M J, Levin B, et al. Guidelines for colonoscopy surveillance after polypectomy: a consensus update by the US Multi-Society Task Force on Colorectal Cancer and the American Cancer Society. CA Cancer J Clin 2006;56(3): 143-159; quiz 184-145.

5. Winawer S, Fletcher R, Rex D, Bond J, Burt R, Ferrucci J, et al. Colorectal cancer screening and surveillance: clinical guidelines and rationale-Update based on new evidence. Gastroenterology 2003;124(2): 544-560.

6. Smith RA, Cokkinides V, Eyre HJ. American Cancer Society guidelines for the early detection of cancer, 2006. CA Cancer J Clin 2006;56(1): 11-25; quiz 49-50.

7. Jackman RJ, Mayo CW. The adenoma-carcinoma sequence in cancer of the colon. Surgery, gynecology and obstetrics 1951;93(3): 327-330.

8. Muto T, Bussey HJ, Morson BC. The evolution of cancer of the colon and rectum. Cancer 1975;36(6): 2251-2270.

9. Schreuders EH, Ruco A, Rabeneck L, Schoen RE, Sung JJ, Young GP, et al. Colorectal cancer screening: a global overview of existing programmes. Gut 2015;64(10): 1637-1649.

10. Hardcastle JD, Chamberlain JO, Robinson MH, Moss SM, Amar SS, Balfour TW, et al. Randomised controlled trial of faecal-occult-blood screening for colorectal cancer. Lancet 1996;348(9040): 1472-1477.

11. Kronborg O, Fenger C, Olsen J, Jorgensen OD, Sondergaard O. Randomised study of screening for colorectal cancer with faecal-occult-blood test. Lancet 1996;348(9040): 1467-1471.

12. Schoen RE, Pinsky PF, Weissfeld JL, Yokochi LA, Church T, Laiyemo AO, et al. Colorectalcancer incidence and mortality with screening flexible sigmoidoscopy. $N$ Engl J Med 2012;366(25): 2345-2357. 
13. Lansdorp-Vogelaar I, Knudsen AB, Brenner H. Cost-effectiveness of colorectal cancer screening. Epidemiol Rev 2011;33: 88-100.

14. Sekiguchi M, Igarashi A, Matsuda T, Matsumoto M, Sakamoto T, Nakajima T, et al. Optimal use of colonoscopy and fecal immunochemical test for population-based colorectal cancer screening: a cost-effectiveness analysis using Japanese data. Jpn J Clin Oncol 2016;46(2):116:125.

15. Wilschut JA, Hol L, Dekker E, Jansen JB, Van Leerdam ME, Lansdorp-Vogelaar I, et al. Costeffectiveness analysis of a quantitative immunochemical test for colorectal cancer screening. Gastroenterology 2011;141(5): 1648-1655 e1641.

16. Lansdorp-Vogelaar I, Knudsen AB, Brenner H. Cost-effectiveness of colorectal cancer screening an overview. Best practice \& research. Clinical gastroenterology 2010;24(4): 439-449.

17. de Wijkerslooth TR, Stoop EM, Bossuyt PM, Meijer GA, van Ballegooijen M, van Roon AH, et al. Immunochemical fecal occult blood testing is equally sensitive for proximal and distal advanced neoplasia. Am J Gastroenterol 2012;107(10): 1570-1578.

18. Brenner H, Stock C, Hoffmeister M. Effect of screening sigmoidoscopy and screening colonoscopy on colorectal cancer incidence and mortality: systematic review and meta-analysis of randomised controlled trials and observational studies. Bmj 2014;348: g2467.

19. Dental and Pharmaceutical Benefits Board (TLV). General Guidelines for Economic Evaluations from the Pharmaceutical Benefits Board. Stockholm, Sweden: Dental and Pharmaceutical Benefits Board, 2003.

20. Gopalappa C, Aydogan-Cremaschi S, Das TK, Orcun S. Probability model for estimating colorectal polyp progression rates. Health care management science 2011;14(1): 1-21.

21. Regionalt cancercentrum. Swedish colorectal cancer registry 2014. Svenska Kolorektalcancerregistret 2014.

22. Luning TH, Keemers-Gels ME, Barendregt WB, Tan AC, Rosman C. Colonoscopic perforations: a review of 30,366 patients. Surg Endosc 2007;21(6): 994-997.

23. SCB. Statistics Sweden. Life Tables 2014. http://www.scb.se/. Accessed July 1, 2016. In. 
24. Lo SH, Halloran S, Snowball J, Seaman H, Wardle J, von Wagner C. Colorectal cancer screening uptake over three biennial invitation rounds in the English bowel cancer screening programme. Gut 2015;64(2): 282-291.

25. Kapidzic A, van Roon AH, van Leerdam ME, van Vuuren AJ, van Ballegooijen M, LansdorpVogelaar I, et al. Attendance and diagnostic yield of repeated two-sample faecal immunochemical test screening for colorectal cancer. Gut 2015; in press.

26. Telford JJ, Levy AR, Sambrook JC, Zou D, Enns RA. The cost-effectiveness of screening for colorectal cancer. CMAJ 2010;182(12): 1307-1313.

27. Burstrom K, Johannesson M, Diderichsen F. Increasing socio-economic inequalities in life expectancy and QALYs in Sweden 1980-1997. Health Econ 2005;14(8): 831-850.

28. Ness RM, Holmes AM, Klein R, Dittus R. Utility valuations for outcome states of colorectal cancer. Am J Gastroenterol 1999;94(6): 1650-1657.

29. Jonas DE, Russell LB, Chou J, Pignone M. Willingness-to-pay to avoid the time spent and discomfort associated with screening colonoscopy. Health Econ 2010;19(10): 1193-1211.

30. Tilson L, Sharp L, Usher C, Walsh C, Whyte S, O'Ceilleachair A, et al. Cost of care for colorectal cancer in Ireland: a health care payer perspective. The European journal of health economics 2012;13(4): 511-524.

31. Pharmaceutical Specialties in Sweden http://www.fass.se/. Accessed July 1, 2016.

32. Board of Health and Welfare. NordDRG.

http://www.socialstyrelsen.se/klassificeringochkoder/norddrg. Accessed November 24, 2016.

33. Heitman SJ, Ronksley PE, Hilsden RJ, Manns BJ, Rostom A, Hemmelgarn BR. Prevalence of adenomas and colorectal cancer in average risk individuals: a systematic review and meta-analysis. $N$ Engl J Med 2009;7(12): 1272-1278.

34. Mandel JS, Bond JH, Church TR, Snover DC, Bradley GM, Schuman LM, et al. Reducing mortality from colorectal cancer by screening for fecal occult blood. Minnesota Colon Cancer Control Study. N Engl J Med 1993;328(19): 1365-1371.

35. Tappenden P, Chilcott J, Eggington S, Patnick J, Sakai H, Karnon J. Option appraisal of population-based colorectal cancer screening programmes in England. Gut 2007;56(5): 677-684. 
36. Tappenden P, Eggington S, Nixon R, Chilcott J, Sakai H, Karnon J. Colorectal cancer screening options appraisal. Cost-effectiveness, cost-utility and resource impact of alternative screening options for colorectal cancer. Report to the English Bowel Cancer Screening Working Group. University of Sheffield; 2004.

37. Goede SL, van Roon AH, Reijerink JC, van Vuuren AJ, Lansdorp-Vogelaar I, Habbema JD, et al. Cost-effectiveness of one versus two sample faecal immunochemical testing for colorectal cancer screening. Gut 2013;62(5): 727-734.

38. Winawer SJ, Fletcher RH, Miller L, Godlee F, Stolar MH, Mulrow CD, et al. Colorectal cancer screening: clinical guidelines and rationale. Gastroenterology 1997;112(2): 594-642.

39. Ko CW, Dominitz JA. Complications of colonoscopy: magnitude and management. Gastrointest Endosc Clin N Am 2010;20(4): 659-671.

40. Parekh M, Fendrick AM, Ladabaum U. As tests evolve and costs of cancer care rise: reappraising stool-based screening for colorectal neoplasia. Aliment Pharmacol Ther 2008;27(8): 697-712.

41. Warren JL, Klabunde CN, Mariotto AB, Meekins A, Topor M, Brown ML, et al. Adverse events after outpatient colonoscopy in the Medicare population. Ann Intern Med 2009;150(12): 849-857, W152.

42. Lee D, Muston D, Sweet A, Cunningham C, Slater A, Lock K. Cost effectiveness of CT colonography for UK NHS colorectal cancer screening of asymptomatic adults aged 60-69 years. Applied health economics and health policy 2010;8(3): 141-154. 


\section{FIGURE LEGENDS}

Figure 1. Schematic figure of the model with its core health-states and possible annual transitions. Squares represent health states and arrows possible transitions with a certain probability to move from one to another health state. The left part of the figure, with dotted lines, represents the initial screening while the right part of the figure with solid lines represents health states and transitions after the screening. During this part transitions are repeated until all simulated individuals are dead. The lower part of the figure presents the different health states in the natural disease progression of known or unknown adenoma/CRC that is used in the model. CRC: Colorectal cancer.

Figure 2. Number of CRC-related death when 1000 hypothetical individuals are simulated in the five treatment arms. All strategies were compared to no screening.

Figure 3. Cumulative incremental cost of screening with OC and FIT when 1000 hypothetical individuals are simulated in the five treatment arms. 
The remainder of the simulated individuals' life

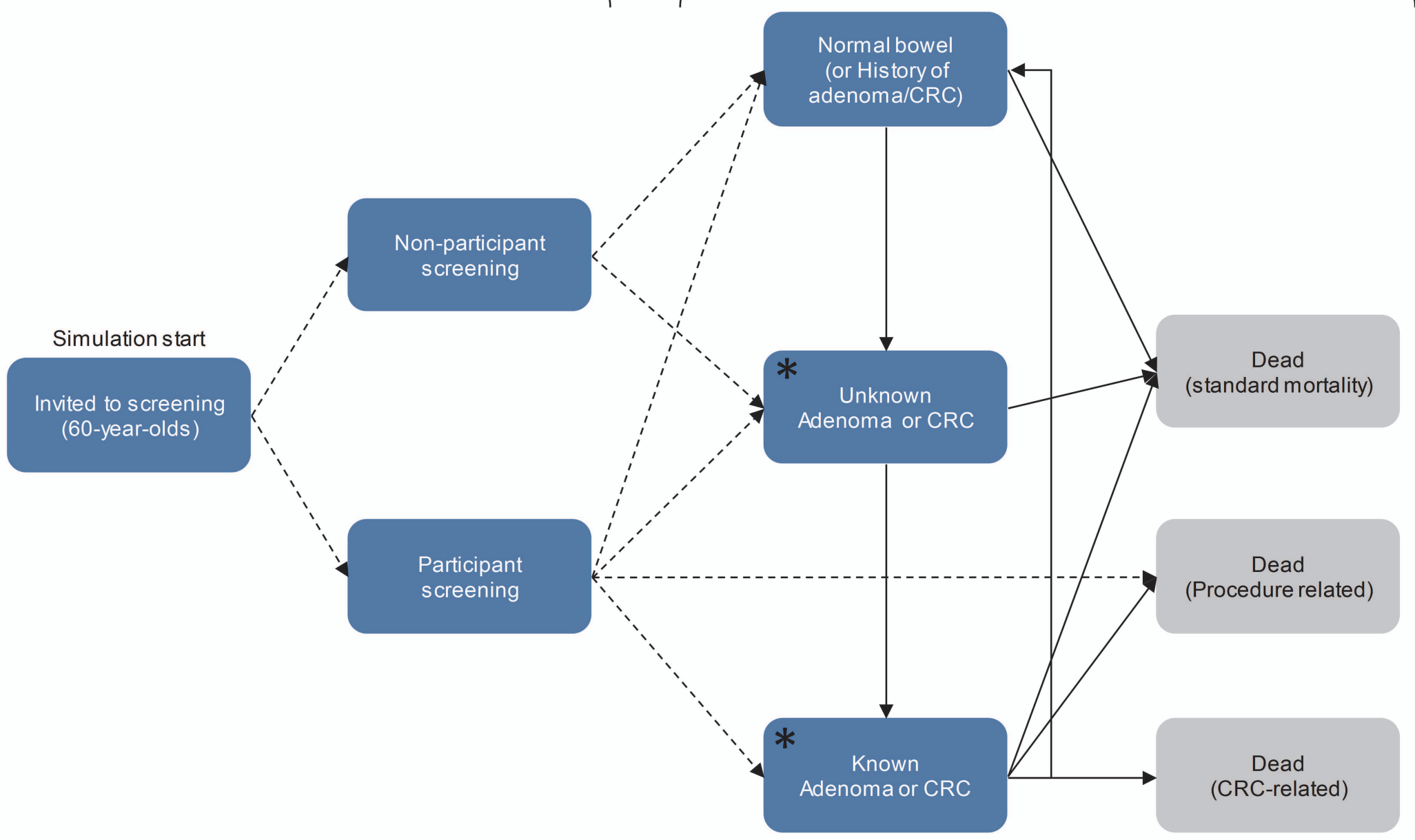

Natural disease progression

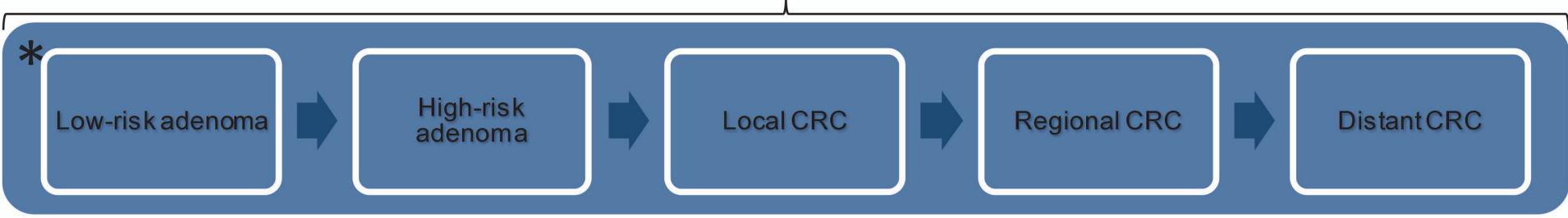




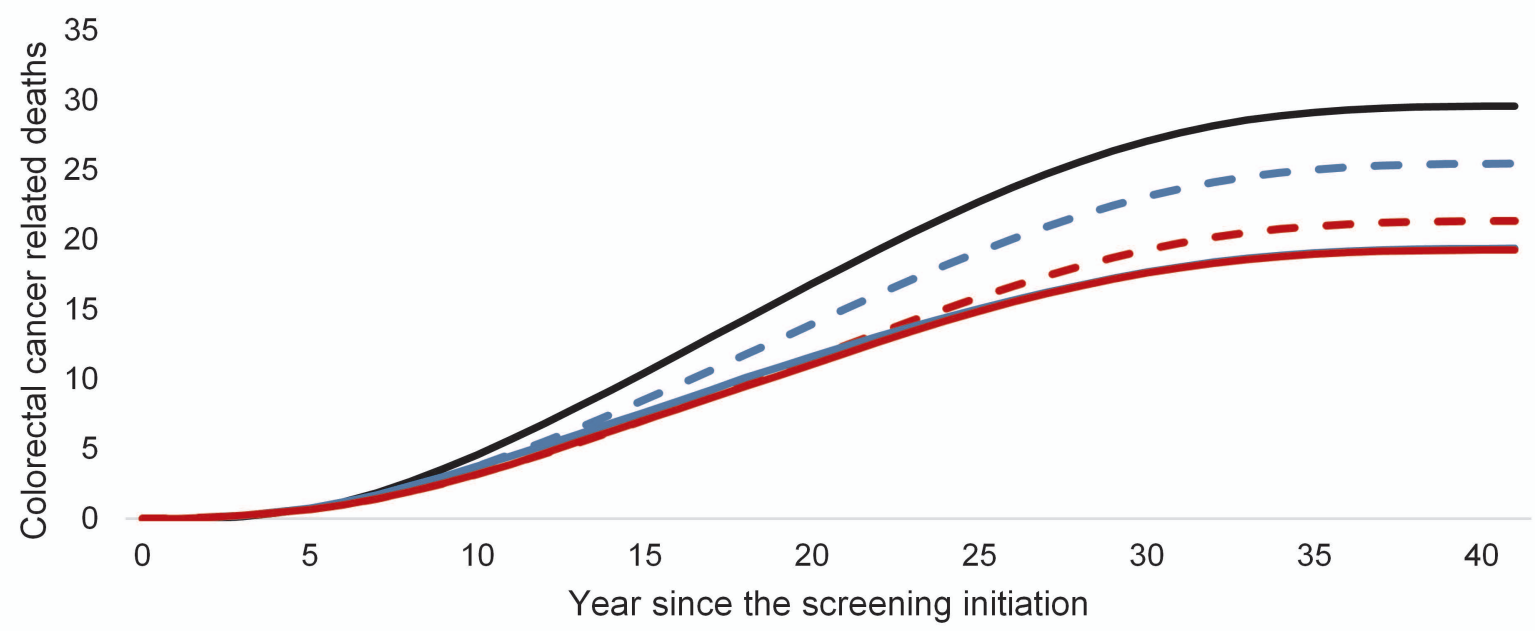

No screening - FIT twice - OC once $\longrightarrow$ Repeated FIT Repeated OC 


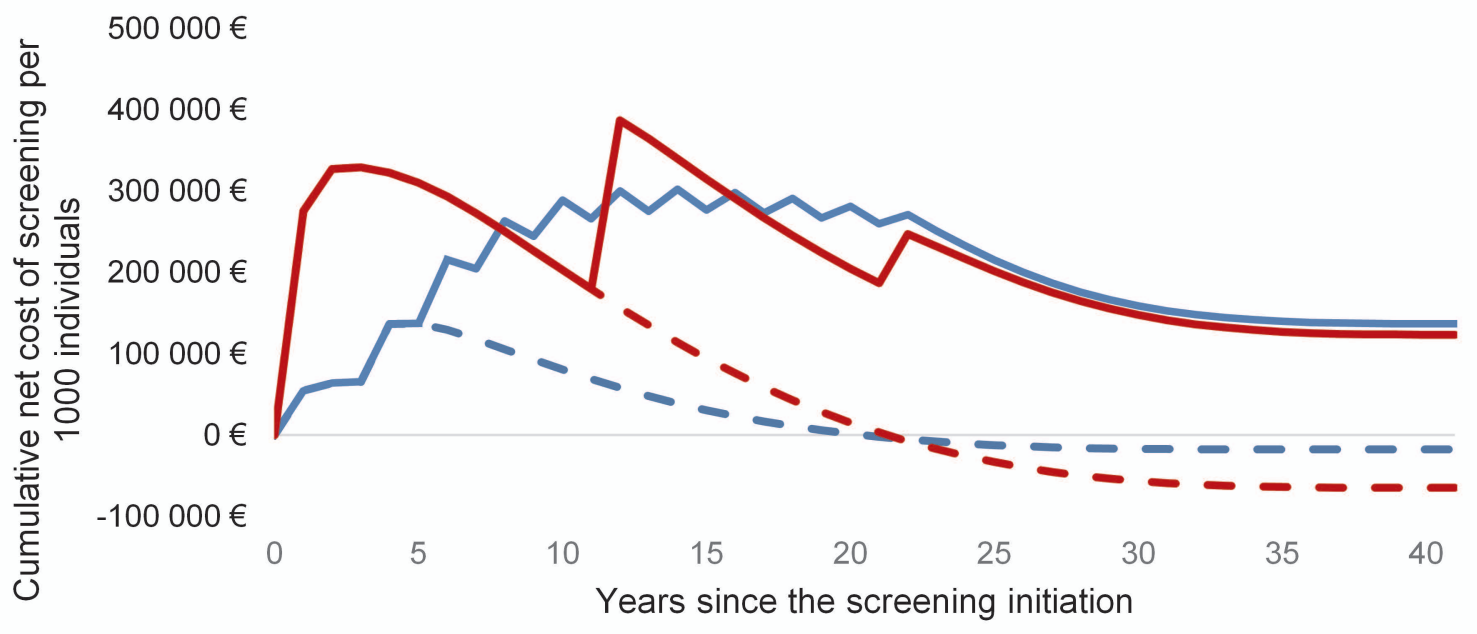

- FIT twice $\quad-$ OC once $\quad$ Repeated FIT Repeated OC 
Table 1. Parameter estimates used in the model.

\begin{tabular}{|c|c|c|c|}
\hline$\underline{\text { Parameters }}$ & Mean value & $\underline{\text { Parameters }}$ & Mean value \\
\hline$\underline{\text { General parameters }}$ & & $\underline{\text { Prevalence at age } 60 \text { years }}$ & \\
\hline Age (base-case) & 60 years & Normal bowel & $0.76^{33}$ \\
\hline Female gender (base-case) & $0.50 *$ & Low-risk adenoma & $0.18^{33}$ \\
\hline Time-horizon & Life-long & High-risk adenoma & $0.052^{33}$ \\
\hline Discount rate & $0.03^{19}$ & Local cancer & $0.0018^{33}$ \\
\hline Attendance rate OC & 0.38 & Regional cancer & $0.0005^{33}$ \\
\hline Attendance rate FIT & 0.50 & Distant cancer & $0.0002^{33}$ \\
\hline Attendance rate colonoscopy after FIT & $0.81^{34}$ & & \\
\hline$\underline{\text { Screening parameters }}$ & & $\underline{\text { Transitions (yearly) }}$ & \\
\hline Expected rate of negative FIT & 0.90 & Normal-to-low-risk adenoma (age 50-64) & $0.007^{20}$ \\
\hline Expected rate of positive FIT & 0.10 & Normal-to-low-risk adenoma (65-74) & $0.008^{20}$ \\
\hline Specificity FIT & $0.93^{17}$ & Normal-to-low-risk adenoma (75+) & $0.004^{20}$ \\
\hline Specificity OC & $1.00^{35}$ & Low-risk-to-high-risk adenoma & $0.02^{20}$ \\
\hline Sensitivity $O C$ & & High-risk adenoma-to-Local cancer & $0.05^{20}$ \\
\hline Low-risk adenoma & $0.92^{26}$ & Local-to-regional cancer & $0.20^{20}$ \\
\hline High-risk adenoma & $0.97^{26}$ & Regional-to-distant cancer & $0.65^{20}$ \\
\hline Colorectal cancer & $0.97^{26}$ & $\underline{\text { New adenoma after polypectomy }}$ & \\
\hline Sensitivity FIT & & Removed high-risk adenoma $\leq 1$ year & $0.25^{5,36}$ \\
\hline Low-risk adenoma & $0.06^{37}$ & Removed high-risk adenoma >1year & $0.04^{38}$ \\
\hline High-risk adenoma & $0.35^{17}$ & Removed low-risk adenoma $\leq 1$ year & $0.18^{5,36}$ \\
\hline Colorectal cancer & $0.88^{17}$ & Removed low-risk adenoma $>1$ year & $0.04^{38}$ \\
\hline$\underline{\text { Complications }}$ & & $\underline{\text { Costs }(€)}$ & \\
\hline Perforations OC & $0.0009^{22}$ & Invitation to screening & $2.70 *$ \\
\hline Bleedings OC & $0.0030^{39}$ & Material FIT-test $* 2$ & $11.00^{40}$ \\
\hline Perforations polypectomy & $0.0009^{22}$ & Lab FIT $* 2$ & $11.00 *$ \\
\hline \multirow[t]{2}{*}{ Bleedings polypectomy } & $0.0087^{41}$ & OC & $650^{32}$ \\
\hline & & Polypectomy & $790^{32}$ \\
\hline Spontaneous detection rate (yearly) & & Quality of life weights & \\
\hline Local & $0.16^{42}$ & Decrement local & $0.08^{28}$ \\
\hline Regional & $0.49^{42}$ & Decrement regional & $0.30^{28}$ \\
\hline Distant & $1.00 *$ & Decrement distant & $0.55^{28}$ \\
\hline
\end{tabular}

*Assumption, OC: Colonoscopy, FIT: Faecal Immunochemical Test. 
Table 2. Results of 1000 individuals invited to screening with OC and FIT compared to no screening.

\begin{tabular}{|c|c|c|c|c|c|c|c|}
\hline & \multicolumn{4}{|c|}{ Compared to no screening } & \multicolumn{3}{|c|}{ Incremental cost per QALY versus: } \\
\hline & Additional cost $(€)$ & Avoided CRC & Added life-years & Additional QALYs & $\begin{array}{c}\text { No screening } \\
(€)\end{array}$ & $\begin{array}{c}\text { OC } \\
\text { once } \\
(€)\end{array}$ & $\begin{array}{c}\text { FIT twice } \\
(€)\end{array}$ \\
\hline OC once & -64800 & 16 & 52 & 49 & -1300 & - & -2000 \\
\hline FIT twice & - 17600 & 7 & 28 & 26 & -700 & Dominated & - \\
\hline OC $10^{\text {th }}$ year & 124600 & 21 & 59 & 56 & 2200 & 26900 & 4800 \\
\hline FIT $2^{\text {nd }}$ year & 136700 & 18 & 54 & 51 & 2700 & 81500 & 6200 \\
\hline
\end{tabular}


Table 3. Two-way sensitivity analyses. All results are compared to no screening per 1000 invited individuals.

\begin{tabular}{|l|r|r|r|r|r|r|r|r|r|r|r|r|}
\hline & Reference & \multicolumn{2}{|c|}{$\begin{array}{c}\text { Participation } \\
\text { (absolute) }\end{array}$} & \multicolumn{2}{|c|}{ Discount rate } & \multicolumn{2}{|r|}{$\begin{array}{r}\text { Prevalence CRC } \\
\text { (age 60y) }\end{array}$} & $\begin{array}{r}\text { Starting } \\
\text { age }\end{array}$ & $\begin{array}{r}\text { Polyp } \\
\text { transitions }\end{array}$ \\
\hline
\end{tabular}

